8. Каржавин В.К. Термодинамическое моделирование сернокислого разложения эвдиалита / XVI Международная конференция по химической термодинамике в России. Т. 1. Суздаль, 1-6 июля, RCCT 2007 (тезисы). Москва (МГУ). 2007. С.73.

9. Каржавин В.К. Физико-химическое исследование процесса высокотемпературного разложения кианита // Проблемы освоения кианитовых месторождений Кольского полуострова, Карелии и Урала. Материалы Всероссийского совещания, посвящённого 80-летию Кольского НЦ РАН. Апатиты: Изд-во К \& М, 2010. С.78-86.

10. Каржавин В.К. Термодинамические величины химических элементов и соединений. Примеры их практического применения. Апатиты: Изд-во Кольского научного центра РАН, 2011. 160 с.

11. Карпов И.К. Физико-химическое моделирование на ЭВМ в геохимии. Новосибирск: Наука, 1981. 248 с.

12. Лурье Ю.Ю. Справочник по аналитической химии. М., 1979. С. 101.

13. Щипцов В.В. Кианит - эффективное сырьё для производства огнеупоров, сферы потребления, производители и мировая торговля // Новые огнеупоры. № 8. 2005. С. 78-82.

14. Berman R.G. Thermobarometry using multi-equilibrium calculations: a new technique, with petrological applications // Canad. Miner. 1991. V. 29. N 4. P. 833-855.

\title{
НОВЫЙ МЕТОД РЕКОНСТРУКЦИИ ОБСТАНОВОК ФОРМИРОВАНИЯ ПРОТОЛИТОВ ДРЕВНЕЙШИХ КОМПЛЕКСОВ
}

Марчук T.C. ${ }^{1}$, Мартынов Е.В. ${ }^{2}$

https://doi.org/10.31241/MIEN.2018.14.23

${ }^{1}$ Апатитский филиал Мурманского государственного технического университета, Апатиты, marchuk@geoksc.apatity.ru

${ }^{2}$ Геологический институт КНЦ РАН, Апатиты

В данной работе описывается подход к реконструкции геодинамических обстановок формирования комплексов докембрия и фанерозоя, основанный на геохимических данных и определяющий достаточно высокую надежность результатов реконструкции. Кольский регион является хорошим полигоном для получения разнообразных данных по реконструкции геодинамических обстановок. Информационной основой исследований является имеющаяся в распоряжении авторов совокупность баз данных по вещественному составу образований докембрия (банк данных «Тиетта») и фанерозоя (литературные данные). Всего было использовано более 20000 полных силикатных анализов. Методологической основой является работа с базой данных, систематизация и сопоставление материалов по геологии, ве- 
щественному составу различных комплексов Кольского региона с использованием оригинальных, не имеющих аналогов как в России, так и за рубежом методов распознавания первичной природы, петрогеохимического моделирования параметров геодинамических обстановок и их изменчивости в ходе развития Земли.

\section{Докембрий}

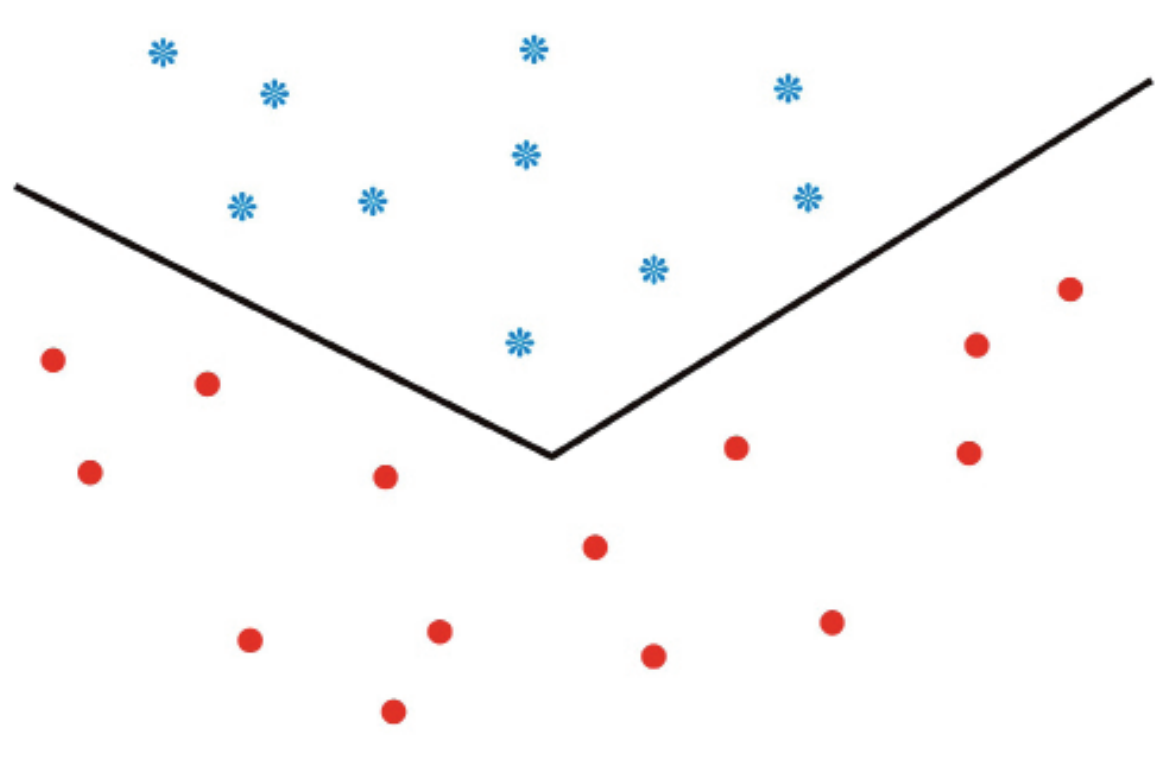

\section{Фанерозой}

Рис.1. Закономерные и статистически значимые отличия петрохимических характеристик метабазальтов докембрия и базальтов фанерозоя.

Результаты многолетних исследований проводимых в рамках нашей лаборатории показали, что процессы эволюции Земли развивались нелинейно. Более того, были установлены закономерные и статистически значимые отличия петрохимических характеристик метабазальтов докембрия и базальтов фанерозоя (рис.1), что должно учитываться при решении задач реконструкции докембрийских образований с использованием фанерозойских эталонов. Таким образом, принцип актуализма нельзя использовать без внесения определенных поправок при изучении геодинамических обстановок докембрия. При проведении параллелей между докембрийскими и фанерозойскими породными комплексами, генетически связанными с определенными режимами, целесообразно исходить из предположения о специфичности докембрийского периода развития планеты, с одной стороны, и некоторой общности в характере протекания геологических процессов. Данный подход был сформулирован достаточно давно как положение о гомологичных рядах геодинамических режимов (Козлов, 1995). 
Особенностями наших подходов к решению задач реконструкции является то, что ищется не просто решение (их может быть много), а устойчивое решение. Устойчивость достигается в том случае, если выборка является «представительной». Проблема заключается в том, что не существует четкого определения «представительной выборки». Мы исходим из того, что наиболее целесообразно сформулировать ее следующим образом: выборка является представительной, если, начиная с некоторого объема, добавление новых данных не влияет на результат решения поставленной задачи. Такая формулировка является аналогом критерия состоятельности статистической оценки в математической статистике. Решение задачи распознавания первичной природы метамерфизованных пород и классификации их по видам нами осуществляется по методике разработанной А.А. Предовским (Предовский, 1980). Естественно могут использовать и другие методики, лишь бы они работали в единой шкале. Информация о химических составах эталонов представлена в виде совокупностей выборок. На данном этапе возможны два варианта: выборки, состоящие только из однозначно классифицированных образцов (выпуклые оболочки не перекрываются), и выборки с перекрытием фигуративных точек химических составов эталонов. Затем из системы выборок с перекрытием нужно получить совокупность «чистых» выборок (без перекрытий). Далее производится сопоставление выборок исследуемых объектов докембрия с эталонами фанерозоя в многомерном пространстве. Для этого может быть использованы различные меры близости: близость до выпуклых оболочек эталонов, центроидное расстояние, среднее расстояние и др. В случае варианта с перекрытиями решение считается достоверным, если результаты реконструкции для выборок с перекрытием и «чистых» выборок совпадают друг с другом.

При сравнении химического состава пород исследуемого объекта докембрия с составами эталонов фанерозоя мы используем только породы основного состава. Кроме того, чтобы избавиться, хотя бы частично, от влияния процессов метаморфизма на химический состав горных пород докембрийских объектов используется следующий приём. Вместо 10 петрогенных элементов $\left(\mathrm{SiO}_{2}, \mathrm{TiO}_{2}, \mathrm{Al}_{2} \mathrm{O}_{3}, \mathrm{FeO}, \mathrm{Fe}_{2} \mathrm{O}_{3}, \mathrm{MnO}, \mathrm{MgO}, \mathrm{CaO}, \mathrm{Na}_{2} \mathrm{O}, \mathrm{K}_{2} \mathrm{O}\right)$ используем 8 параметров химического состава, преобразуя параметры ( $\mathrm{FeO}, \mathrm{Fe}_{2} \mathrm{O}_{3}$, $\mathrm{MnO})$ в новый параметр $\Sigma \mathrm{FeO}$. Это позволяет нам работать в 8-ом признаковом пространстве, где каждая отдельная порода представлена фигуративной точкой в этом пространстве.

До сих пор используемый нами разработанный метод распознавания геодинамической обстановки, в которой формировался изучаемый объект докембрия, заключался в следующем. Смещение химических составов объектов докембрия относительно составов эталонов фанерозоя можно описать с помощью двух ранее найденных одним из авторов обобщенных показателей. Поэтому имеется возможность реконструкции обстановок формирования объектов докембрия (рис. 2). Как можно увидеть использование двух обоб- 


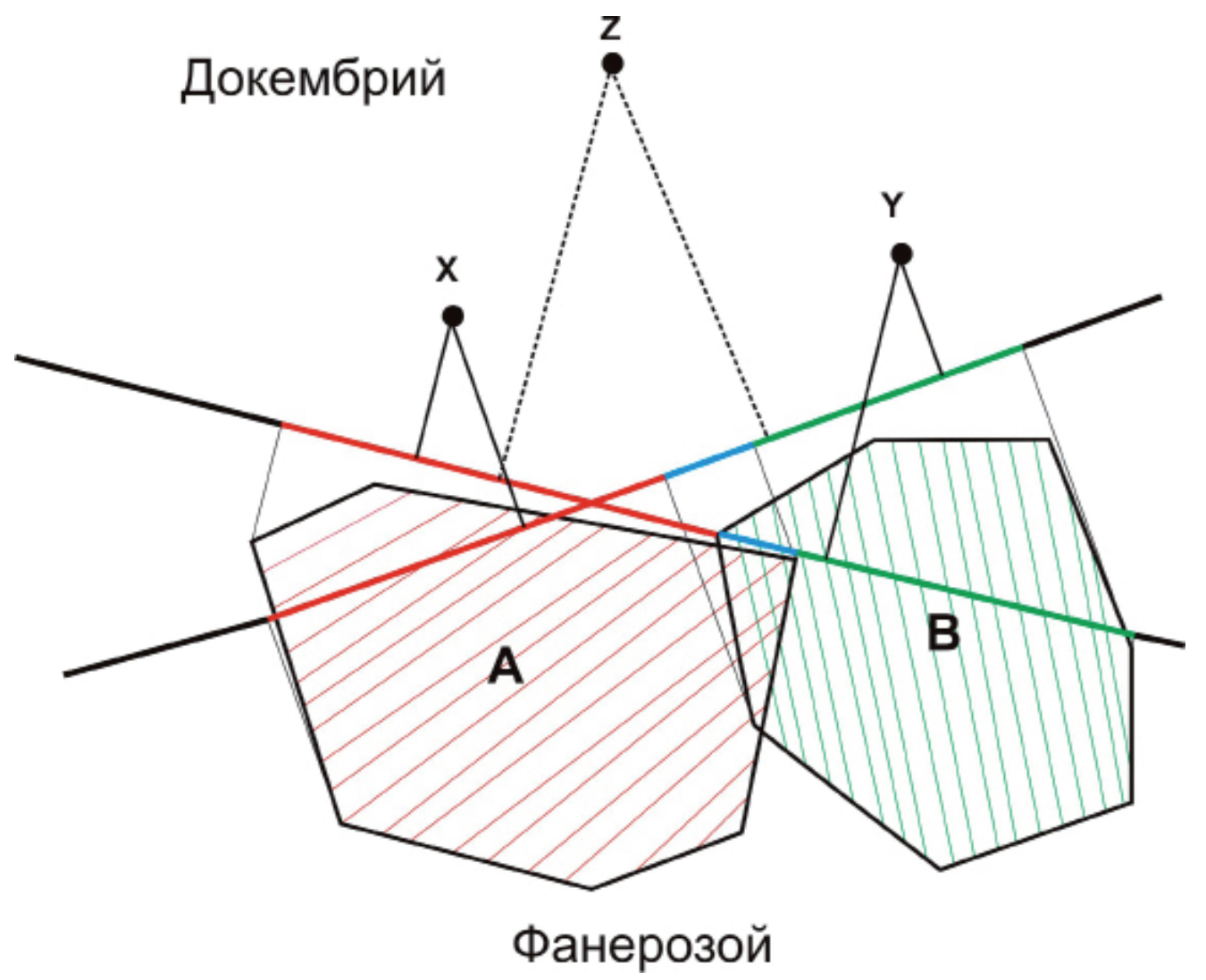

Рис. 2. Принцип реконструкции на основе двух обобщенных показателей, смещение фанерозой $\rightarrow$ докембрий. Объект х относится к обстановке А, объект у-к обстановке В, для объекта z- достоверного решения нет.

щенных показателей при реконструкции может дать неопределенный результат: на одной разделяющей гиперплоскости в качестве решения получаем один режим, а на другой - иной. Наши исследования показали, что эта неопределенность возрастает с возрастом исследуемых комплексов докембрия. Поэтому возникла необходимость изучить следующую проблему: можно ли найти метод для получения более определенного результата или это предел подхода для реконструкции распознавания геодинамических обстановок на основе сопоставления по химизму объектов докембрия и фанерозоя.

Для решения данной проблемы авторы предлагают новый метод распознавания геодинамических обстановок формирования докембрийских объектов. Его можно описать следующим образом. Смещение объектов докембрия относительно эталонов фанерозоя в 8-мерном признаковом пространстве (объекты докембрия и эталоны фанерозоя представленые множествами фигуративных точек) мы пытаемся описать при помощи поверхности 2-го порядка, разделяющей объекты докембрия и фанерозоя. При этом критерием того, что эта поверхность является разделяющей, служит статистическая значимость отличия между множествами фигуративных точек каждого объекта с множествами проекций этих точек на вышеуказанную поверхность, а множества фигуративных точек объектов докембрия и фанерозоя расположены по разные стороны этой поверхности (рис. 3). Мы используем оптимальную разделяющую поверхность, для которой минимальная бли- 
зость всей совокупности объектов к поверхности - максимальна. В частности, можно выбрать поверхность из условия,

$$
(z-Y) S_{2}^{-1}(z-Y)^{\prime}-(z-X) S_{1}^{-1}(z-X)^{\prime}=2 * \ln \frac{\left|S_{1}\right|^{1 / 2}}{\left|S_{2}\right|^{1 / 2}},
$$

где $S=\frac{1}{n_{1}} S_{1}+\frac{1}{n_{2}} S_{2} \quad$ и $\mathrm{S}_{1}, \mathrm{~S}_{2}$ и $\mathrm{S}_{1}, \mathrm{~S}_{2}-$ оценки ковариационных матриц для химических составов пород объектов докембрия и фанерозоя, а X,Y - оценки их средних (Родионов и др., 1987).

При распознавании геодинамической обстановки в которой формировался изучаемый объект докембрия мы должны работать с совокупностями фигуративных точек для объектов докембрия и эталонов фанерозоя расположенных на построенной разделяющей поверхности. Последние позволяет использование различных мер близости для проекций фигуративных точек химических составов объектов докембрия и фанерозоя оценки достоверности полученных результатов с использованием статистических критериев. Ввиду того, что распределение фигуративных точек объектов не соответствует ни одному из известных классических, используется непараметрические критерии. Мы предпочитаем критерий Пури-Сена-Тамуры который устойчив относительно нарушение нормальности (и даже унимодальности) распределения изучаемых случайных величин, а также относительно наличия в сопоставляемых выборках аномальных наблюдений. Как было уже упомянуто, мер близости существует множество. Выбор одной из них

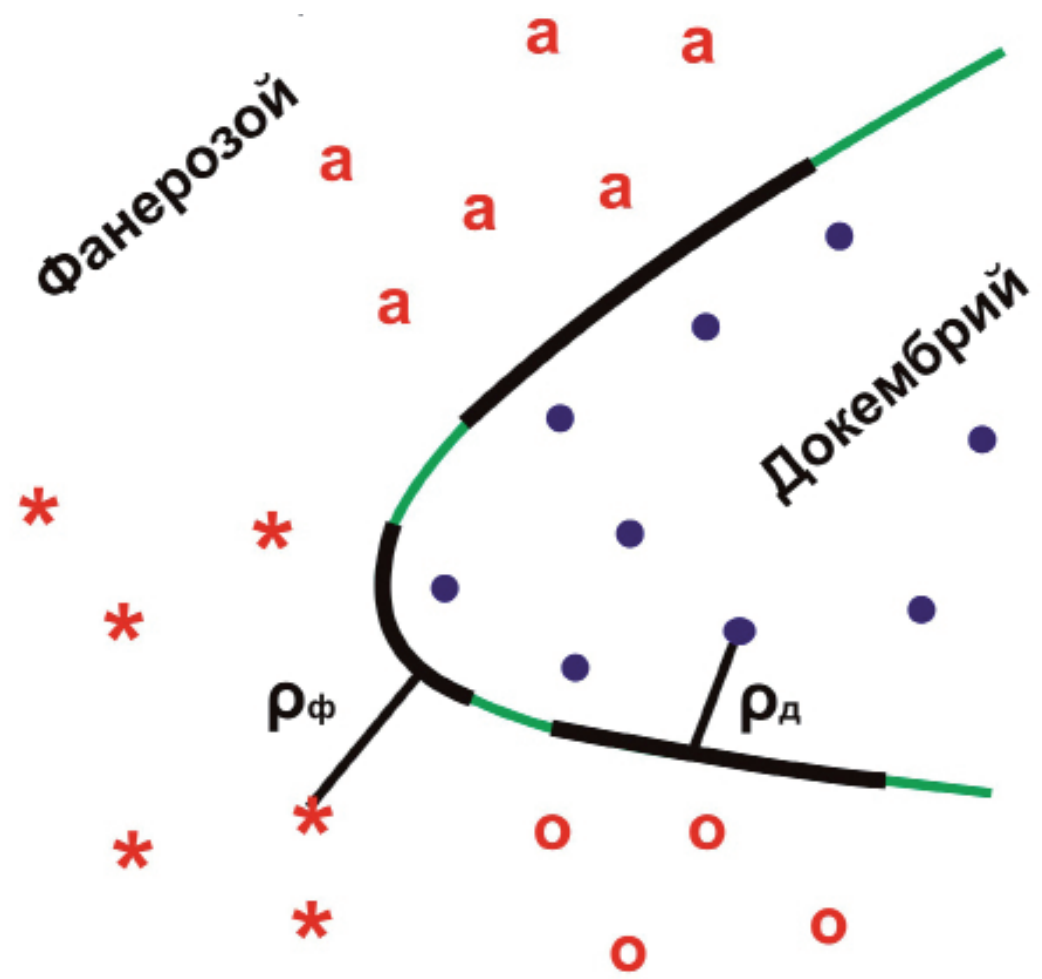

Рис.3. Реконструкция обстановок на основе использования поверхности 2-го порядка. 
затруднителен ввиду отсутствия научно обоснованных аргументов в чью или иную пользу. Поэтому мы используем следующий прием. Проводим реконструкцию режима формирования исследуемого докембрийского объекта с использованием различных мер близости и сравниваем результаты. Совпадение решений для большинства использованных мер близости следует считать достоверным решением.

\section{Список литературы}

1. Козлов Н.Е. Вещественный состав метаморфических комплексов высокобарных гранулитовых поясов и проблема формирования их протолитов (на примере Лапландских гранулитов). Автореферат докторск. дисс. С-Пб. ИГГД. 1995. $36 \mathrm{c.}$

2. Мартынов Е.В. Реконструкция обстановок формирования протолитов метаморфических комплексов докембрия на основе статистического моделирования их характеристик по петрогеохимическим данным. Автореф. дисс. к.г.-м.н. Спб. 1997. 23 с.

3. Предовский А.А. Реконструкция условий седиментогенеза и вулканизма раннего докембрия. Л.: Наука. 1980. 152 с.

4. Родионов Д.А., Коган Р.И. Голубева В.А. и др. Справочник по математическим методам в геологии. М.: Недра. 1987. 335 с. 